\title{
Multiple cis-regulatory elements regulate distinct and complex patterns of developmental and wound-induced expression of Arabidopsis thaliana $4 C L$ gene family members
}

\author{
Bahram M. Soltani • Jürgen Ehlting • \\ Björn Hamberger • Carl J. Douglas
}

Published online: 29 August 2006

(C) Springer-Verlag 2006

\section{Erratum to: Planta \\ DOI 10.1007/s00425-006-0296-y}

Images generated by Hans-Peter Stuible and Erich Kombrink, Max-Planck-Institut für Züchtungsforschung, Cologne, Germany showing the expression patterns of At4CL1::GUS, At4CL2::GUS, and At4CL3::GUS in transgenic Arabidopsis seedlings, were incorrectly used in Figure 3 of this manuscript (DOI number 10.1007/s00425-006-0296-y). The proper Figure 3 is shown below, and replaces the original Figure 3 published in error. The authors acknowledge that Drs. Stuible and Kombrink generated the At4CL1::GUS and At4CL3::GUS lines shown in Figure 3, and regret the improper inclusion of their images in the original Figure 3.

The online version of the original article can be found at http://dx.doi.org//10.1007/s00425-006-0296-y.

B. M. Soltani

Genetics Graduate Program, University of British Columbia,

Vancouver, BC, Canada V6T 1 Z4

B. M. Soltani · B. Hamberger · C. J. Douglas $(\bowtie)$

Department of Botany, University of British Columbia,

Vancouver, BC, Canada V6T 1Z4

e-mail: cdouglas@interchange.ubc.ca

J. Ehlting

Institute for Plant Molecular Biology,

Centre National de la Recherche Scientifique,

67000 Strasbourg, France 


\section{At4CL1::GUS}

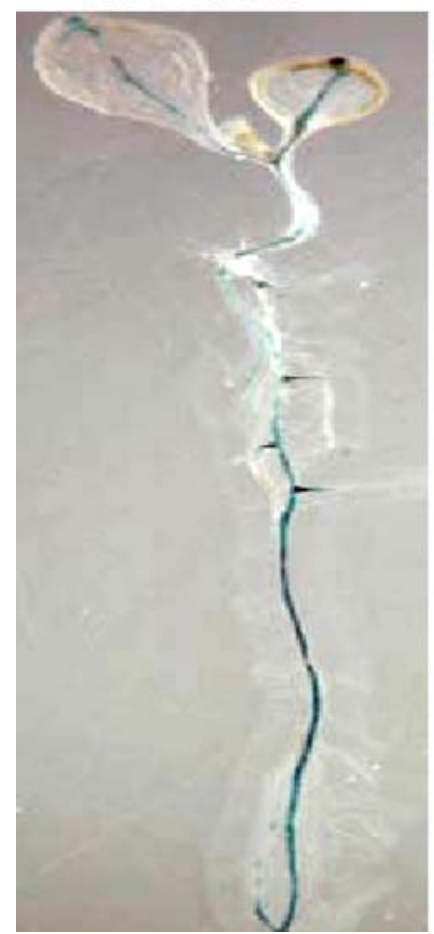

Fig. 3 Developmentally regulated GUS expression specified by At4CL promoters. GUS expression in representative seedlings transgenic for At4CL1::GUS, At4CL3::GUS and At4CL4::GUS

\section{At4CL2::GUS}

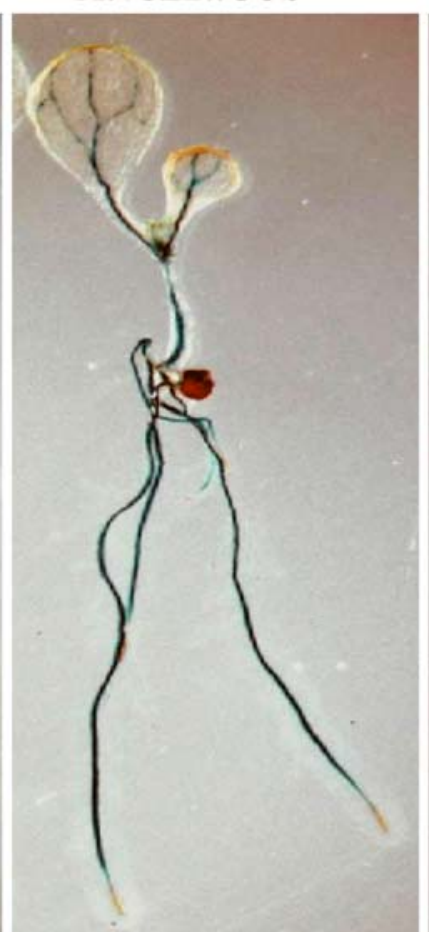

fusions shown in Fig. 2c, and the 1.6-kb At4CL2 promoter::GUS

fusion shown in Fig. $2 \mathrm{c}$ are shown

\section{At4CL4::GUS}
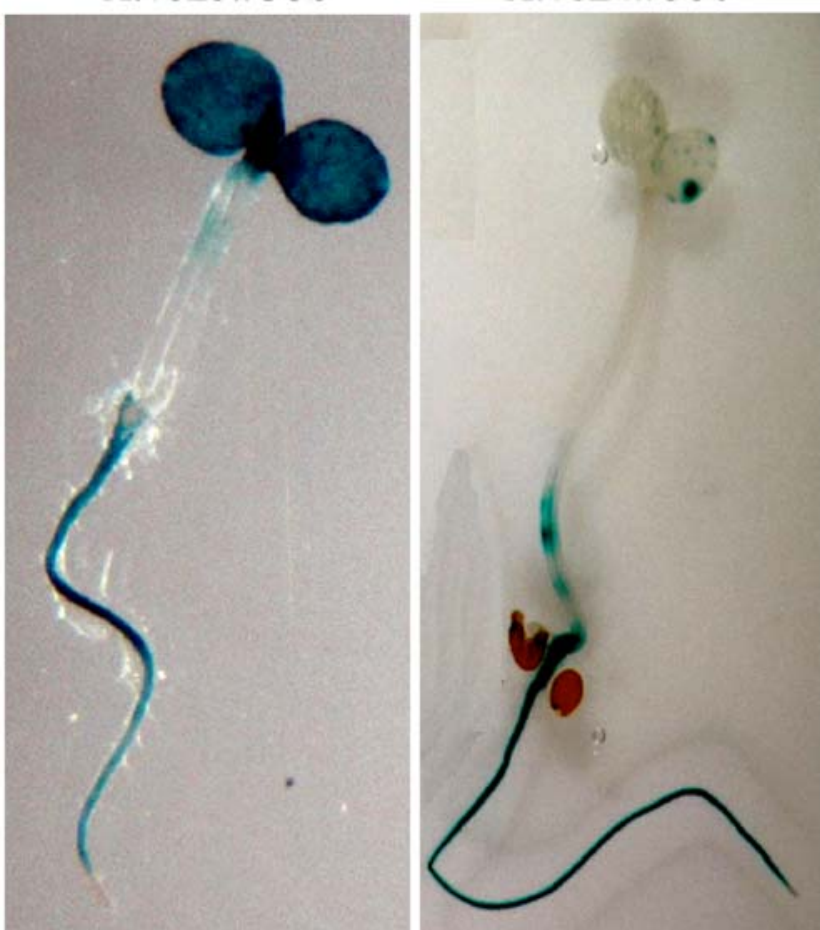